\title{
SCIENTIFIC COSMOLOGY AND RELIGIOUS OR THEOLOGICAL COSMOLOGY FROM AN ISLAMIC PERSPECTIVE
}

\author{
Md Sabbir Hossain*
}

\begin{abstract}
The interconnectedness of science and religion - two radically different areas in essence but with striking connexions in terms of scope has entailed reconsideration and reconstruction of some notions, particularly pertaining to areas of religion. This paper presents existing conceptions of one of religion's fundamental constituent elements, theology. In discussing theology, with a brief account of its Islamic counterpart, the current paper indulges in an analysis of some of its vital elements. Upon exploring theology, focus is placed upon the discipline of cosmology and its two-fold practices, namely the scientific and theological. Most significantly, a newly articulated, well-categorised framework is provided for theological cosmology, which paves the way for further profound dialogue on the scope and intersection of theology and science in the context of cosmology. In addition, the article attempts to distinguish theological as well as scientific cosmological perceptions and articulate a well-organised analysis containing key discrepancies. Such resounding divergence can produce some fundamental principles for studying the cosmos - both from a scientific as well as theological perspective.
\end{abstract}

Keywords: Cosmology, Theology, Science, Natural Theology, Islam.

\section{Introduction}

For ventures into observing and understanding the universe as a whole, religion is increasingly set aside and considered irrelevant, especially in the modern milieu. Except in the context of religious discourse, generally speaking cosmology which conducts the said venture - is exercised from an exclusively scientific perspective. Therefore, the interpretation of the findings of cosmology entirely ignore the potential role and contribution of religion. It can be said that such an attitude is not merely due to the secularist, naturalist and reductionist epistemology of modern-day science, but also to a lack of understanding of the concept, definition, scopes and elements of religious cosmology. In a similar manner, religious cosmology continues to either entirely ignore or extensively customise scientific cosmology as per its applicability and similarity of conjectures regarding the physical cosmos presented by theology. The relevance and significance of 
scientific cosmology in any comprehensive religious/theological cosmology can only be apprehended by consulting the framework, characteristics and paradigm of the latter. Furthermore, theological cosmology in any contemporary religious discourse severely lacks a precise, well-defined, comprehensive and universally accepted framework and paradigm, especially in light of the encroachment of scientific cosmology. ${ }^{1}$

In fact, theological cosmology has been overshadowed by the prominence of its counterpart. Hence, the primary objectives of this treatise are to re-examine our conceptions of theology and cosmology; contrive and establish a much needed framework and paradigm for theological cosmology, highlighting its major constituting components and their sub-components, territories and parameters; and determine the potential grounds of interaction and intersection between scientific and theological cosmology. It can be expected that such an approach will entail a discussion of the major differences between these two disciplines.

Another compelling rationale for the current treatise is that our epistemology, perception and perspective alter as our material world changes over time, in parallel to civilisational progress. Due to some fundamental changes in human epistemology in recent times, it is required to re-evaluate our understanding and previously-determined understanding of religious cosmology's scope and framework.

\section{Defining Theology}

Regardless of the immense diversity in existing definitions of religion, any discussion of this concept will certainly involve, one way or the other, a theological element, either discreetly or conspicuously, concisely or intricately. A religion - regardless of its magnitude in terms of number of subscribers, its region of influence or duration of existence - is not a religion unless it includes a theological component, which essentially defines the religion itself and forms the basis for it to develop and encompass other dimensions of human science, such as ethics, law, cosmology etc. Also, it is in the domain of theology that one of the oldest and most compelling mysteries of the universe lies: is there a Creator? This millennia-long question has not been resolved as far as atheists and agnostics are concerned, up until now. However, theology throughout its long historical journey has presented a great many diverse arguments in favour of God's existence - making this particular issue a crucial topic for theology. Once God's existence is established, theology seeks to explain God's creation (i.e. the universe) and the nature of His relationship with it.

Since it has been established so far that theology is by far the most central component of a religion, in this context the crucial question arises: 'what 
precisely is theology?' Prior to establishing a comprehensive definition, it appears somewhat appealing to explore the historical development and context of the term 'theology'. Werner Jaeger claims that theology was a creation of Greek philosophers, with Plato being the first to coin the term, which constituted one of the four chief terms used in his philosophical works (as well as Aristotle's). Plato used this term in his masterpiece 'Republic', in which there is a section called 'Outlines of Theology', which distinguished the mythical approach from the rational approach to the issue of the Divine. ${ }^{2}$ Theology, by the etymology of the term, is the logos - a word which has a number of applications such as rationale, theory, description, account etc. - of God. ${ }^{3}$ Hence, it is a discourse about God.

Theology is an immensely comprehensive discipline - in fact, far more in depth than any other subject - dealing with both God (who is infinite) and the universe (which is finite), as described by a late nineteenth-century Christian theologian, W. G. T. Shedd (1820-1894). ${ }^{4}$ A classical definition of theology from a theologian's perspective is: "the science of God; of His Being, Attributes, and Providence; in other words, of God in Himself and of the universe in relation to Him." ${ }^{5}$ An early twentieth-century theologian holds that theology was the jewel of Christendom's intellectual realm and, in its days of supremacy, considered to be "the science of God." However, under the antagonistic scrutiny of modern secular-intellectual trends, it has adopted a rather more modest definition: "the intellectual expression of religion." ${ }^{\prime 6}$ With God in the centre of its discourse, theology seeks to define and characterise the values and meaning of a religion. It is worth mentioning that in certain aspects there exist fundamental differences between theology and other disciplines, such as ethics, religious law etc. A subtle line might be drawn between religion and theology, especially when, strictly speaking, the former is mostly considered or emphasised as the norm, while the latter is seen as a science. As such, despite dealing with ultimately the same subject matter, theology cannot be co-extensive with religion, as religion deals with duties pertaining to God, while theology deals with the consciousness of the relation between God and His creation. ${ }^{7}$

\section{Islam and Theology}

Unlike in Christianity, where theology is central, in Islam theology is described by a number of experts as the third major subject of intellectual discourse, preceded by jurisprudence and mysticism. Commonly known as kalam, this term literally denotes 'speech' but, if properly translated, essentially refers to 'dialectic theology'. ${ }^{8}$ As far as the origin of Islamic theology is concerned, there is no universally accepted theory. A considerable number of experts, especially orientalists from the West, hold that Greek philosophical concepts (centred 
on natural theology) and early Christian theology influenced Muslim thinkers significantly, ultimately paving the way for the emergence of Muslim theology as a discipline. Muslim scholars, including a great many from the West, tend to advocate that socio-political disputes fuelled theological controversies within early Muslim communities, ultimately giving rise to theology.

Topics of theological concern arising in the early Muslim world were: a) the status of sinners in the religion as well as in the community, b) the analysis of the concept of God's unity, essence, existence, and attributes, c) God's relation to the cosmos, especially mankind, d) the paradox of pre-determination and human free-will, e) eschatology, f) the createdness of the Qur'an (i.e. the nature of the Qur'an's existence prior to revelation), and g) reason and revelation. In recent phases of Islamic theological debate, a great number of newly-formed domains, issues, controversies, and subject areas have emerged and become dominant. These can credibly be divided into two major categories: intraMuslim and inter-Muslim-Non-Muslim. The former encompasses interpretation and implementation of Islamic scriptures in the contemporary context; Islamic legal issues incorporating theological aspects; formulating Islamic ethics; redefining Muslim identity and culture etc. Due to colonisation, globalisation and global migration, the Muslim world has increasingly been exposed to nonMuslim parts of the world and thus a number of recently-emerging theological concerns mainly pertain to the spread of modern socio-economic, political and intellectual ideologies, as well as science's influence over the Islamic worldview and epistemology. Modern scientific developments in epistemology have posed extreme challenges to classical Islamic theological doctrines, particularly with regard to physical as well as theological cosmology.

\section{Theology and Other Religious Elements}

\section{Faith and Theology}

A common misconception, particularly amongst non-experts in religious studies, is that theology is basically faith, and vice-versa. Faith could be by nature intuitive, subjective and idiosyncratic, or even irrational. Theology, however, is a systematic study of religion. Nevertheless, since theology is not an empirical science, the human faculty of interpretation and presupposition ultimately makes faith quite pertinent to theological discourse. In fact, these two coincide recurrently in human intellectual, as well as ordinary, life as the former (i.e. theology) is in essence a reflection of the latter (i.e. faith). However, the former is certainly not solely based on the latter. Perhaps, it could be said that one of the constituent elements of theology is a guided faith. Certainly, faith without clarification, reference, inference, or investigation is not compatible with the science of theology. ${ }^{9}$ 


\section{Scripture, Prophethood and Theology}

Religious scriptures, texts or inscriptions with either Godly or humanly origins are of great religious significance and their propositional substances are interpreted predominantly via the faculties of theology. A theological discipline is based primarily on scriptural authority and/or prophetic authority. The correlation between revelation and theology is one-way; deductions reached via theological analysis do not amend the contents of the revealed knowledge originating from scripture. As far as prophethood is concerned, an ordinary mind, unaware of the pattern of progressive development in theology, would perhaps presume that a prophet or a messenger (one who claims to be the bearer of Godly revelation or authority) is essentially the founder, organiser and developer of theology. In fact, close observation of the historical development of theology, especially in the Abrahamic religions, suggests quite the contrary, i.e. prophets are not actually theologians. A prophet-preached message does provide theological insight or necessarily produce or articulate a systematised comprehensive theological discipline. ${ }^{10}$ This materialises under succeeding generations, after sporadic interpretation of the prophetic tradition, re-examination of prophettaught theological conceptions from a new perspective, or the addition of new dimensions to a discourse that generate a controversy which paves the way for even more controversies, eventually forming a substantially lengthy theological debate and a gradually matured science. ${ }^{11}$

\section{Classifications of Theology}

The earliest classifications of theology were the three types of theology that Saint Augustine mentioned: mythical theology, political theology and natural theology. Mythical referred to the creations of writers and poets, while political was the state of religion and its cults. Natural theology, on the other hand, emerged primarily as a field in which philosophers and theologians could study nature and its relationship to the Divine. Natural theology, which will be discussed in detail in the following section, originated from Greek philosophy. ${ }^{12}$ Some of the more modern classifications of theology include philosophical theology, scriptural theology, apophatic theology, systematic theology, dogmatic theology, practical theology, historical theology, eschatological theology etc. Since the current discussion intends to deal with cosmology, a brief discussion of natural theology is presented below.

\section{Natural Theology}

Since theology is basically the discussion of God, His existence, nature and relation to the cosmos, when the term 'natural' is applied to it, it imposes "a 
limitative, restrictive, and determinative force. What is still in hand is theology - the account of God; but that account is to be a natural account."13 Natural theology is purely based on human reason, observation, and the study of nature, which will ultimately enable man to comprehend the Creator. In principle, natural theology entails no account of revealed knowledge about God. In fact, absence of revelation distinguishes natural theology from most other theological categories. In the contemporary era, the dialogue between science and religion, particularly theology, is principally based on the implications of modern scientific findings for natural theology. It is also a dynamic branch of theology as our understanding of the cosmos tends to change quite radically. ${ }^{14}$ Once an attempt is made to formulate a framework for theological cosmology, the role of natural theology will be brought in.

The following sections will present a discussion of the discipline of cosmology and its two major types, namely scientific and theological, with a particular focus on the latter's framework and paradigm. That discussion will pave the way for exploring the existing divergences, potential scopes of interaction, and dependencies between these two crucial types of cosmology.

\section{Cosmology}

From ancient mythology and scattered tribal religions to the world's major religions, the origin of man and the cosmos has been a major source of discourse, controversy and speculation. In that respect, cosmology has been one of the most predominant academic research fields of the ancient as well as the modern intellectual realm. It will undoubtedly continue to be so due to two primary rationales: that not even a tiny fraction of the infinity vast cosmic ocean has been explored and humanity has still not satisfied its inquisitiveness.

Various understandings of the term cosmology exist, differing in their meaning, reference, and constituents in so many diverse and drastic ways that the term has turned into a polysemous word. The word 'cosmology', however, originates with the Greek terms kosmos (world or world order) and logos (reason) ${ }^{15}$ and deals with the origin, structure, order, and fundamental governing laws of the macrocosmic as well as, to a certain extent, microcosmic realms. Cosmology as a fascinating sub-discipline of astrophysics has made substantial advances, particularly in the last few decades, claimed to be "the golden era of cosmological physics."

Arguably, there are two prime spheres couched in the discipline of cosmology. Despite the most prevalent modern perception of cosmology being scientific, a religious or philosophical cosmological discourse also exists, encompassing the drastically different (if not polar opposite) domain of theological cosmology. 
Therefore, the discipline of cosmology can be categorised into two major classifications: religious and scientific or empirical. It is widely perceived that it is the former which has a profound impact on theology. Nonetheless, modern studies of religious scriptures have yielded a quite complex debate on the potential relationship between scientific data and theological theories. Consequently, a prominent contemporary topic of scholarly discourse is the potential for a possible reconciliation between the evolutionary knowledge of the visible universe gathered under the banner of science and the sacred, scripture-based understanding of the cosmos delineated by theological study. This correlation is somewhat irrevocable, irrefutable and conspicuous. It is of great significance to explore these two domains' characteristics and ultimate objectives.

Moreover, there is practically no religious system which is not cosmological not in that term's conventional scientific definition, but rather in a comprehensive and inclusive sense. As Emile Durkheim commented, “....the first systems of representation which man made of the world and of himself were religious in origin. There is no religion that is not a cosmology as well as a speculation on the divine." 17 Perhaps it is somewhat opaque to note how cosmology, being purely an empirical discipline, might require theological motivation in its endeavours, especially in modern times, unless a thorough investigation is conducted which would reveal the compresence of theological enticement as well as scientific curiosity behind such endeavours. However, theologians, philosophers, scholars, and ethicists have developed theological tools, doctrines, and exegesis that are either directly or indirectly anchored in scientific cosmological theories. Periodically, cosmological models have been adopted throughout the intellectual history of theology as theological principle. However, theological models may not be restricted to or strictly aligned with one particular scientific theory. In the realm of religious (primarily theological) discourses, cosmology in its wideranging sense may denote the origin of physical reality; its ultimate purpose; its ultimate destiny; the relationship of this cosmos to the ultimate reality etc. A baffling manifestation of theological penumbra in the intellectual territory of cosmology, specifically in the origin and development of cosmological discourse, is unassailable.

\section{Scientific Cosmology}

From a comprehensive and inclusive perspective, cosmology was, until the emergence of the twentieth century, a joint venture of science, philosophy and theology. Now, however, it has been through a scientific transformation. Consequently, it now intends to unify knowledge from other scientific branches (such as astronomy, physics, mathematics etc.) to provide a unifying and 
fundamental cosmic picture, rather than studying a piece of the picture using other branches of knowledge. Being a cross-disciplinary field, cosmology has been related to or involved with other major subjects dealing with celestial bodies. In recent years, academicians have begun merging astronomy and particle physics in the common field of cosmology. However, an important difference between subjects like astrophysics and cosmology is that astrophysics is more concerned with the physical laws that structure celestial objects such as galaxies, planets, stars etc., whereas cosmology is primarily interested in the study of the universe as a whole, on a grand scale of time and distance. Unlike other branches of modern science, cosmology leaves cosmologists with a major obstacle: much of the existing universe is not accessible for empirical observation. Regardless of unparalleled epistemological precision, therefore, modern cosmology still produces models which are, to a certain degree, beyond experiential verification.

Scientific cosmology aims to seek and observe the existing evidence in order to enlighten the enquirer about the ultimate origin, evolution, structure and fate of the universe, while also accumulating and articulating the underlying cosmic processes and laws governing the entire universe. Hence, this remarkable field of study deals with mindboggling questions like whether the universe is static or dynamic; whether it is open or closed; its birth, age and whether it will come to an end; its primary constituents; and so on. Ultimately, a description of the universe is presented by the cosmological model.

The first and foremost task of scientific cosmology lies in defining what the universe or cosmos is. These two seemingly synonymous terms are predominantly used when referring to the entirety of existence, i.e. matter, particles, energy, time, space. The universe seen via a cosmological glass is basically the largest scaled structure in existence, in which all the laws of physics can be applied, and in which all other particles, matter, energy, and other entities interrelate. Cosmology attempts to conceptualise the origin of the current universe by reconstructing, in principle, its initial states. The subjects included in this endeavour are the nature of the expansion of the universe after its initial state; the origin, structure and evolution of large scale objects such as galaxies, stars, and planets; the nature and role of sub-atomic particles; and cosmic entities such as dark matter, black holes etc. Cosmology is perhaps the only discipline among contemporary scientific subjects to encompass significant analysis of the objects and events beyond the physically observable universe as it attempts to explain the origin of the universe itself. Such an endeavour entails theoretical assumptions, suppositions and hypotheses based on mathematics and physics. 


\section{Religious or Theological Cosmology}

Cosmology is one of the major themes or vital areas of theology itself. Every major world religion has its own cosmology, the nature of which may or may not be pragmatic from a purely scientific perspective. As Alfred North Whitehead writes, "The theme of cosmology is the basis of all religions." 18 Prior to commencing a discussion of theological cosmology, it is worthwhile to try and discover the origin of religious cosmology. Why would a religion, considering its definition and nature, have a cosmology?

If God is at the core of a religion's discourse, then so too is the relation between God and His creation, with the realm of creation being categorised as the cosmos. In an attempt to determine, define and describe the origin, nature, development and ultimate fate of the cosmos in relation to God's decree and intention, a cosmology is generated based on either sacred scriptural authority, religious discourse, intellectual venture into the natural world, or a combination of all these things. If a definition was to be given to religious cosmology, it would be the study of the entire cosmos from a religious perspective, in its physical as well as metaphysical forms, with regards to its relation to its origin (generally God) and ultimate purpose. A number of factors influence the nature, characteristics, findings and even parameters of such a study. It is the study of nature that includes a variety of socio-economic, historical, civilisational and environmental factors that shape a society's corresponding religious cosmology. The process might as well be vice-versa, i.e. a religious cosmology can potentially become an influential ideology or force, shaping and influencing a society and its constituent elements.

The notion or domain of religious cosmology differs quite radically from religion to religion. For instance, as far as Islamic cosmology is concerned there exist two extremes. One includes the discourse of science and religion, merely including occasional references to the physical realm in the Divine scriptures. Such an approach cannot be defined as cosmology in any substantive sense of the term as the latter should be a holistic and comprehensive approach, while this is rather selective under the banner of science and religion. ${ }^{19}$ The other extreme, however, perceives cosmology not as a discipline or discourse pertaining to the study of physical reality, but "as an application of principles of a metaphysical order to the cosmic domain." ${ }^{20}$ This trend can be noticed amongst classical Muslim scholars. For instance, Ikhwan al-Safa's hierarchy of being postulates that there are nine major stages or domains of being, starting from the highest (God) and ending with the beings of the world. ${ }^{21}$ 


\section{The Framework and Paradigm of Theological Cosmology}

Theological cosmology can potentially offer the framework for a multifaceted cosmic existence, i.e. a grand-scale threefold cosmos comprising: i) a physical cosmos, the one which is primarily explored, understood and interpreted via the language of science; ii) a cosmos of intangible beings, which is essentially beyond this physical cosmos or parallel to it but that nevertheless relates to the physical one in a number of ways; and iii) a future cosmos in relation to the current one, which basically accommodates all potential eschatological realities. Such a conceptual theological cosmology must entangle all existent beings and non-beings, other than God Himself. From a scientific cosmological perspective, what is cosmically non-existent can very well be an existing entity in the realm of theological cosmology so long as it is verified by theological or scriptural sources.

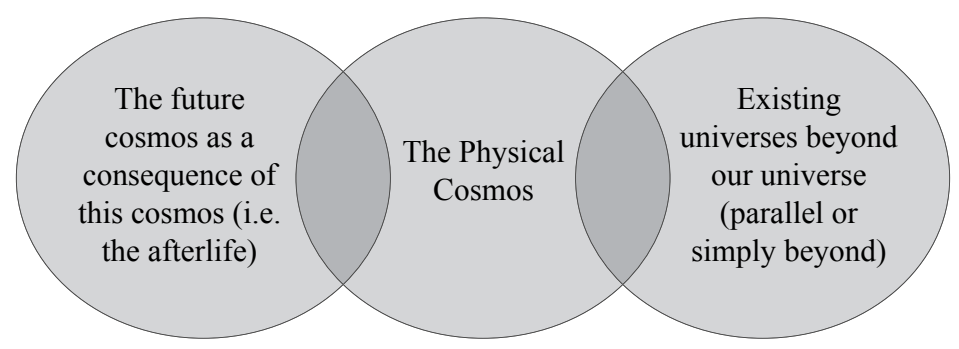

If a comprehensive and well-defined paradigm of theological cosmology is to be established, a detailed discussion of these three cosmic realities is in order.

Religious, i.e. theological, cosmology ought to first define the parameters of the cosmos, after which should come cosmogony, which should include the nature or characteristics of God's creation, particularly with regard to the underlining purpose of origination etc. Then comes the notion of evolution, determining the key elements and fundamental structure of the cosmos, including its teleological aspects. Eventually, the ultimate fate of the cosmos is considered, which might include the possibility of a relation or transition to a subsequent cosmos.

With regard to this endeavour of making sense of the physical cosmos, the sources and methodological aspects necessary to do so are to be clarified at the outset, as religion/theology is not meant to provide the details of our physical reality. Although a physical cosmology is to be formulated based primarily on the divine sources, the interpretation of the data has to be based on knowledge acquired by scientific cosmology as well as natural theology. This process is explained in the following section where the nature and scope of interaction between scientific cosmology and theological cosmology is discussed. 
Metaphysical cosmology would be one of the most significant components of a theological cosmology and would first of all recognise both the metaphysical reality that exists in parallel to physical reality (i.e. the reality beyond this reality) and its relevance. This cosmology would basically deal with common unseen entities (such as angels, devils etc.) and events which are empirically incomprehensible.

It would also embark on a journey to define the roles, position and responsibilities associated with those entities in the physical realm, in line with metaphysical and teleological rationales. Religious worldviews also fall under this category, which might occasionally include dialogues over ethical issues. As, according to theological discourse, a Creator or Superior Being is usually actively or passively involved in physical cosmic affairs, the nature of the relationship between the Creator and His creation is an important subject for theological cosmology. For instance, from an Islamic theological viewpoint, the universe is teleological and God is the essential condition of the mechanism upon which the universe operates. The orderliness and uniformity of the cosmos is attributed not merely to observable chains of cause and effect, but rather to God. ${ }^{22}$

Almost all the major world religions, especially the Abrahamic religions, provide a glimpse of a forthcoming consequential reality, generally involving two destinations (paradise and hell) preceded by an accountability session (Day of Judgement). In certain religious discourses, accounts of this reality are available quite extensively; a separate segment, entitled eschatological cosmology, therefore ought to be formed. As far as Islamic theology is concerned, eschatology is a major concern. In the Qur'an - the primary source of Islamic theology eschatology is described in such detail that the nature of human existence can be derived from it. For instance, Islamic eschatological cosmology postulates that humanity will not merely have a spiritual existence in either paradise or hell, but rather will have a dualistic existence comprising mind as well as body. ${ }^{23}$ This particular branch of theological cosmology cannot possibly have any source other than Divinely revealed scripture(s) and legitimate prophethood.

The figure below demonstrates and summarises the three major constituent components of theological cosmology, along with their sub-divisions, as discussed in this section: 


\section{Theological Cosmology}

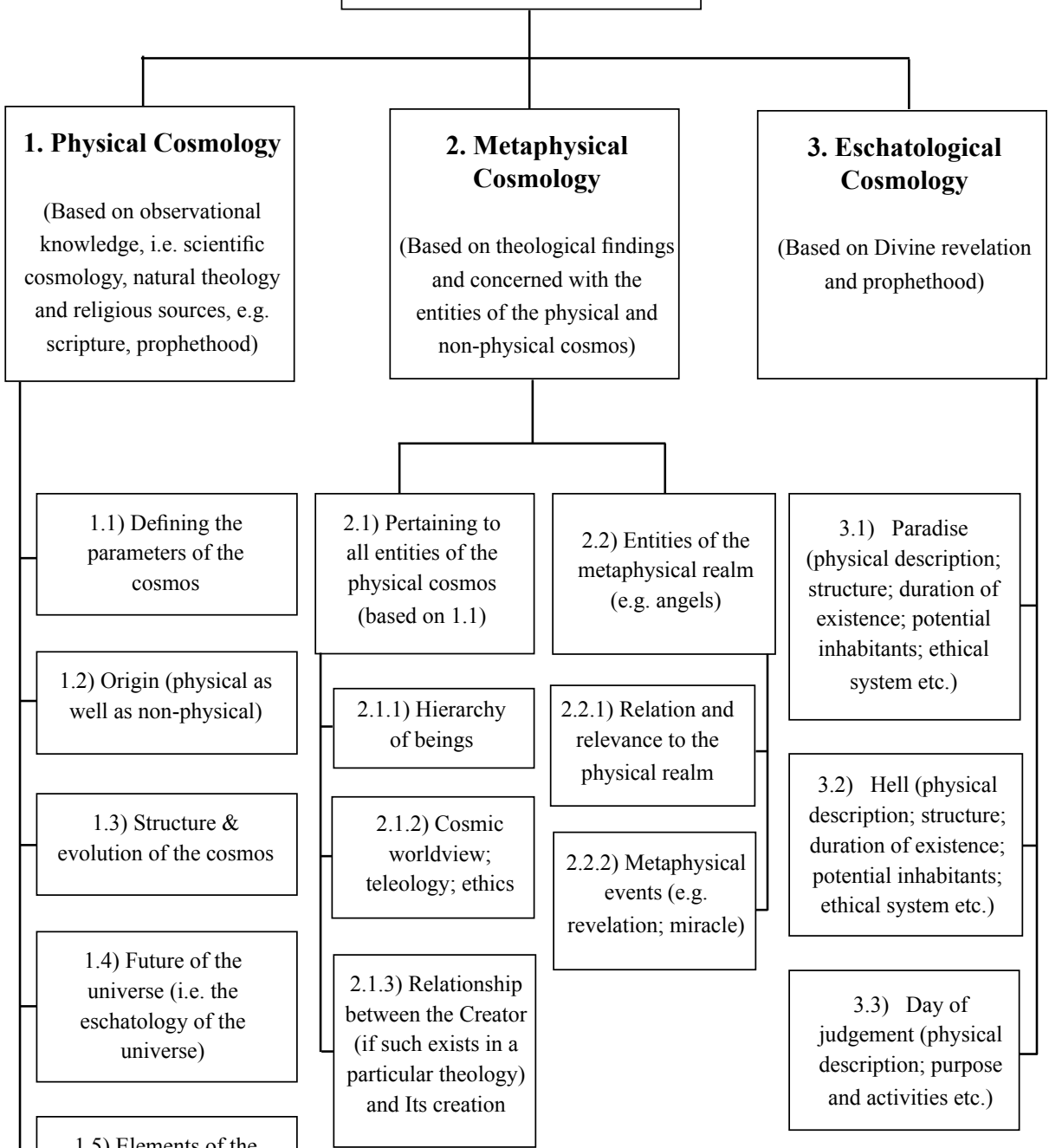

1.5) Elements of the physical universe (e.g. time, space); governing laws 


\section{How Can Scientific Cosmology and Theological Cosmology Interact?}

Since theology is not a mere belief system, but rather a rational, comprehensive and systematic framework which enables a truth-seeking mind to comprehend and contemplate the relationship between this reality and the ultimate reality, theologians are required to consider the cosmos since it is a creation of God and the reality in which we live - hence the intersection of theology and cosmology. On the other hand, scientific cosmology is the reason why contemporary theists do not solely see the cosmos as a mere theistically-created object run by super-natural powers. Rather, the perception is that the cosmos is operated by empirically observable laws. Therefore, the role, subject area and prospects of contemporary theological cosmology have considerably changed.

The nature of theological cosmology is, needless to say, categorically different from that of scientific cosmology. However, there is a need for interaction between the former and the latter for the sake of the fulfilment of both their endeavours. As for the theological enterprise, in order to make sense of physical reality, i.e. the cosmos, theology must study that reality from a purely observational standpoint, i.e. from a scientific cosmological standpoint. Without a thorough examination of the physical cosmos, a theological cosmology is unlikely to formulate a credible cosmological model as it will otherwise rely heavily on assumptions and speculations - bearing in mind that providing scriptural evidence for those suppositions would not be justified as scripture is not meant to deliver detailed descriptions of the physical realm. Turning to scripture would therefore be a categorical error in this particular context. Consider, for instance, the great number of philosophers as well as theologians who have formulated theological cosmological models based on the principle that the cosmos is static; it is now apparent that such models have no credibility. Likewise, scriptural accounts of the universe from ancient religious communities are categorised as myths in the modern context, primarily due to the advancement of scientific cosmology. Therefore, scientific cosmology ought to be a pre-requisite for theological cosmology, particularly with regard to the first component, i.e. physical cosmology, mentioned in the previous section. Theological cosmology requires consideration of scientific cosmological findings prior to or while: 1) interpreting scriptural information regarding the physical universe, 2) making sense of the physical realm, and 3) understanding the underlying driving forces and laws of nature.

The physical aspects of theological cosmology must be studied and formulated via a systematic approach, which can be presented thus: all accounts of the physical cosmos ought to be extracted from the divine sources via thematic study and theological methodologies (i.e. theological paradigms). Such data is then to 
undergo an interpretative process based on natural theology and contemporary scientific cosmology. ${ }^{24}$ This stage will ultimately develop a physical cosmology for a theological context. Such a physical cosmology is bound to be labile, as it is grounded in existing scientific knowledge and human rationale. Hence, a significant part of theological cosmology, unlike other branches of theology and religion, is dynamic.

If scientific cosmology is an utter necessity for theological cosmology, then what role should the latter play in the domains of the former, especially in the context of contemporary scientific culture? Science, unlike other branches of knowledge, has been through a rapid and extreme transformation, particularly in the past few decades, with modern cosmology undoubtedly evincing the most extreme transformation of all. Modern cosmology, despite its extrapolation of physics (especially astrophysics), mathematics, quantum mechanics etc., tends to be interested exclusively in quantitative aspects, entirely discarding teleological implications which are, nevertheless, inseparable. This modern trend results in a rather incomplete picture of the cosmos, ignoring or simply failing to answer the fundamental queries that only theology can deal with. Hence, it is quite evident that scientific cosmology ought to expand its parameters in order to accommodate teleological features of the cosmos and pave the way for a holistic and integrated cosmology, allowing any observer to envisage the cosmos in its entirety. Therefore, it is proposed that scientific cosmology should render some of its queries to theology, queries such as: what existed prior to the origination of the universe; what is God's role in the cosmos; what is the teleology of the cosmos; what are the eschatological aspects, and so forth. Theological cosmology can provide a metaphysical framework for such queries, something otherwise absent in scientific cosmology.

\section{Theological Cosmology vs. Scientific Cosmology}

Prior to examining the potential areas where theological cosmology and scientific cosmology are bound to cross paths, the major divergences in effect between them must be scrutinised. Hence, some fundamental differences are summarised below: 


\begin{tabular}{|c|c|}
\hline Theological Cosmology & Scientific Cosmology \\
\hline $\begin{array}{l}\text { Theological cosmology is concerned } \\
\text { with cosmic reality in its entirety, be it } \\
\text { in the physical or non-physical realm }\end{array}$ & $\begin{array}{l}\text { Scientific cosmology only } \\
\text { accounts for the physical universe, } \\
\text { comprising the entities which can } \\
\text { be scientifically comprehended and } \\
\text { observed, if not physically then at } \\
\text { least mathematically or scientifically }\end{array}$ \\
\hline $\begin{array}{l}\text { The origin of the universe (or universes) } \\
\text { is, generally speaking, attributed to an } \\
\text { external being or deity (i.e. God) }\end{array}$ & $\begin{array}{l}\text { By reconstructing (at least in } \\
\text { principle) the initial state of } \\
\text { creation, the origin of the universe } \\
\text { is speculated to be a cosmic } \\
\text { phenomenon }\end{array}$ \\
\hline $\begin{array}{l}\text { Includes the very fundamental question, } \\
\text { 'WHY did the universe originate in the } \\
\text { first place?' }\end{array}$ & $\begin{array}{l}\text { Interested only in 'HOW did the } \\
\text { universe come into existence in the } \\
\text { first place?' }\end{array}$ \\
\hline $\begin{array}{l}\text { Deeply interested in the ultimate } \\
\text { purpose of the universe }\end{array}$ & $\begin{array}{l}\text { The purpose of the universe, } \\
\text { regardless of its presence or absence, } \\
\text { is irrelevant }\end{array}$ \\
\hline $\begin{array}{l}\text { Not obliged to provide an in-depth, } \\
\text { detailed description of cosmic entities } \\
\text { and phenomena }\end{array}$ & $\begin{array}{l}\text { The primary task is to study and } \\
\text { describe all cosmic objects and } \\
\text { phenomena }\end{array}$ \\
\hline $\begin{array}{l}\text { Three major sources: i) Scripture and } \\
\text { prophethood, ii) Natural theology and } \\
\text { rational discourse, and iii) Scientific } \\
\text { findings }\end{array}$ & All relevant scientific sources only \\
\hline $\begin{array}{l}\text { Prone to subjective views and } \\
\text { interpretation, resulting in major } \\
\text { discrepancies between models over } \\
\text { different eras }\end{array}$ & $\begin{array}{l}\text { Prone to restrict or limit knowledge } \\
\text { due to the limitations placed on } \\
\text { access to the study of cosmic entities } \\
\text { and events }\end{array}$ \\
\hline $\begin{array}{l}\text { Theological speculation and } \\
\text { assumption can have an influential role } \\
\text { in the construction of a cosmological } \\
\text { model }\end{array}$ & $\begin{array}{l}\text { Assumptions are based on empirical } \\
\text { knowledge and discernible natural } \\
\text { phenomena }\end{array}$ \\
\hline $\begin{array}{l}\text { Certain parts of its model may not be } \\
\text { directly verifiable }\end{array}$ & $\begin{array}{l}\text { Models must be verifiable by } \\
\text { mathematical or other scientific } \\
\text { methods }\end{array}$ \\
\hline
\end{tabular}




\begin{tabular}{|l|l|}
\hline $\begin{array}{l}\text { Comprises three primary types of } \\
\text { cosmic reality: the physical universe; } \\
\text { parallel/independent/co-existing } \\
\text { universes; new universe(s) in relation } \\
\text { to the current one (i.e. afterlife) }\end{array}$ & $\begin{array}{l}\text { Any other reality save for the } \\
\text { physical universe is cosmically void } \\
\text { or non-existent, except in speculation }\end{array}$ \\
\hline $\begin{array}{l}\text { The notion of existence in theological } \\
\text { cosmology often comprises a multi- } \\
\text { levelled hierarchy }\end{array}$ & $\begin{array}{l}\text { As it is primarily based on the } \\
\text { principles of natural science, there is } \\
\text { only one level of existence, namely } \\
\text { the physical }\end{array}$ \\
\hline $\begin{array}{l}\text { Methodologies or approaches of study } \\
\text { are teleological }\end{array}$ & $\begin{array}{l}\text { Methodologies are limited to } \\
\text { quantitative forms }\end{array}$ \\
\hline
\end{tabular}

\section{Conclusion}

It is now indisputably palpable that scientific cosmology and theology cosmology are inseparable for the sake of fulfilment of each discipline's ultimate endeavour, specifically when it comes to the latter. Considering the relevance and need for scientific cosmology in formulating an all-encompassing theological cosmological model, new attempts are to be taken in order to articulate a legitimate, rational and comprehensive contemporary theological cosmology, especially in Islamic intellectual dialogue. On the other hand, in view of the differences and diverse scopes of these two disciplines presented in this article, scientific cosmology can confidently hand over some of its queries to its counterpart, namely theological cosmology, and in due course to theology. In a contemporary theological discourse, the framework for theological cosmology established in this article will certainly provide a well-organised, up-to-date and comprehensive theological cosmological model. In addition to the modern implications, such framework can be applied in organising classical contributions thematically, and consequently, well-ordered classical theological cosmological theories and models can be formulated.

\section{Policy Recommendations}

- The vast majority of work on Islamic cosmology dates to the classical Muslim era. There is therefore a need for a modern Islamic cosmology which would have a precisely defined paradigm, set of cosmological principles and an inclusive nature in terms of its sources. 
- In addition to the twofold sources of Islamic knowledge (Qur'an and Sunnah), rationally assimilated knowledge (i.e. science) must be incorporated into Islamic theological cosmology as per a pre-determined principle and paradigm in order to produce a more comprehensive and up-to-date scheme.

- A thorough realisation and awareness of the differences between scientific cosmology and its theological counterpart ought to assist a modern mind in comprehending the existence of the metaphysical realm rationally and theologically. Therefore, in modern Islamic theological cosmology, such differences are to be included and presented for the audience.

- It is essential to bear in mind that the construction of a modern Islamic cosmology does not necessarily mean a dismissal or obliteration of classical Muslim cosmology. Rather, it merely implies a re-visiting and re-construction of paradigms, sources, and interpretations. The proposed modern Islamic theological cosmology and its classical version can certainly co-exist.

\section{Notes}

* Md Sabbir Hossain Master (Research) in Islamic Studies, Department of Theology and Philosophy, Universiti Kebangsaan Malaysia (UKM). Email: sabbirhr@gmail.com.

1. By 'encroachment of scientific cosmology' we mean the recent advancement of scientific cosmology, which has moved beyond expectation, overcoming previously un-crossable limits, allowing cosmologists to confidently postulate theories which attempt to explain major cosmic events which occurred billions of years ago. Consequently, this makes religious cosmology increasingly less relevant when understanding the cosmic theatre.

2. Werner Jaeger, The Theology of the Early Greek Philosophers: The Gifford Lectures 1936 (London: Oxford University Press, 1948), 4.

3. James H. Stirling, Philosophy and Theology: The First Edinburgh University Gifford Lectures (Edinburgh: T \& T Clark, 1890), 22.

4. William G. T. Shedd, Dogmatic Theology (New York: Charles Scribner's Son, 1888), 16.

5. John H. Blunt, Dictionary of Doctrinal and Historical Theology (London: Rivingtons, 1923), 758.

6. Douglas C. Macintosh, Theology as an Empirical Science (New York: Macmillan, 1919), 1.

7. Blunt, Dictionary of Doctrinal and Historical Theology, 758.

8. Juan E. Campo, Encyclopedia of Islam (New York: Facts on File, 2009), 668.

9. Once cosmology enters the discussion, the role of faith becomes a vital point in order to determine the legitimacy of theological cosmology, in contrast to 
mythological cosmology.

10. Ignaz Goldziher, Introduction to Islamic Theology (New Jersey: Princeton University Press, 1981), 67.

11. Later, I intend to demonstrate that scriptural and prophetic authority/knowledge are among the primary sources of theological cosmology.

12. Jaeger, Theology of the Early Greek Philosophers, 2-4.

13. Stirling, Philosophy and Theology, 22.

14. It is this particular branch of theology which ought to determine the methodological aspects of theological cosmology pertaining to the description of the physical realm.

15. Nicholas Campion, Astrology and Cosmology in the World's Religions (New York: New York University Press, 2012), 4.

16. Yurij Baryshev and Pekka Teerikorpi, Fundamental Questions of Practical Cosmology: Exploring the Realm of Galaxies (Dordrecht: Springer, 2012), 1.

17. Emile Durkheim, The Elementary Forms of Religious Life, trans. Carol Cosman (Oxford: Oxford University Press, 2001), 8.

18. Alfred North Whitehead, Process and Reality: An Essay in Cosmology (New York: The Free Press, 1978), 349.

19. Numerous works have been published under the banner 'Qur'an and Science', including discussions on Qur'anic verses referring to the heavenly bodies. Books and articles composed on this theme do not necessarily present a comprehensive Qur'anic or Islamic cosmology. Instead, they merely attempt to prove that the Qur'an contains scientific miracles.

20. Seyyed Hossein Nasr, 'Cosmology,' in The Different Aspects of Islamic Culture, Science and Technology in Islam, ed. A.Y. Al-Hassa (Paris: UNESCO, 2001), 361.

21. Seyyed Hossein Nasr, An Introduction to Islamic Cosmological Doctrines: Conceptions of Nature and Methods for its Study by the Ikhwan Al-Safa, AlBiruni, and Ibn Sina (London: Thames and Hudson, 1978), 51-2.

22. Ismail Razi Al Faruqi, Al Tawhid: Its Implications for Thought and Life (Herndon, VA: IIIT, 1992), 50-1.

23. Fazlur Rahman, Major Themes of the Quran (Kuala Lumpur: Islamic Book Trust, 1999), 112.

24. Contemporary scientific cosmology refers to any particular era's existing cosmology approached from a scientific perspective. 